\title{
Nuclear medicine training and practice in Portugal
}

\author{
Rosário Vieira • Gracinda Costa
}

Published online: 20 April 2013

(C) Springer-Verlag Berlin Heidelberg 2013 after completing the general internship. At present, multispecialty physicians are not common.

\section{Organizational workforce}

By the end of 2012, there were 33 departments of nuclear medicine in Portugal. As illustrated in Fig. 1, there is a high concentration of nuclear medicine services in the three main cities in Portugal: Porto, Coimbra and Lisbon. There are 12 public and 21 private departments. Most of the public ones, ten hospital units, have been awarded full or partial training capabilities and, for the first time in 2013, a fully equipped private hospital will also host an internship.

There are 63 gamma cameras and 11 positron emission tomography (PET) scanners installed throughout the national territory. Currently, there are 53 active working nuclear medicine specialists and 15 residents, for a population of 10.5 million inhabitants in Portugal. Fourteen physicians $(\cong 26 \%)$ work part-time at a public institution and part-time at a private facility. Recently, there has been a tendency towards working at a single institution: 20 work only in the public and 19 only in the private sector.

\section{Training resources and organization}

In order to obtain the title of Nuclear Medicine Specialist, 5 years of training are necessary; the first year consists of a general internship with a strong emphasis on internal medicine and general surgery as well as general practice. The remaining 4 years consist of training in the nuclear medicine specialty itself, but includes some internships in other areas, namely 3 months in radiology and 1 month in cardiology [1].

At the moment, 15 residents are undergoing nuclear medicine training in 7 departments ( 3 in the north, 1 in the centre and 3 in the south of the country). Table 1 summarizes the residents' distribution, according to the year of

Nuclear Medicine Department, Hospital da luz, Av. Lusíada n.

100 ,

1500-650 Lisbon, Portugal

e-mail: rvieira@hospitaldaluz.pt

G. Costa

Nuclear Medicine Department, Centro Hospitalar e Universitário de Coimbra, Praceta Prof. Mota Pinto, 3000-075 Coimbra, Portugal

e-mail: gracindamcosta@gmail.com 
Fig. 1 Geographic distribution of nuclear medicine departments

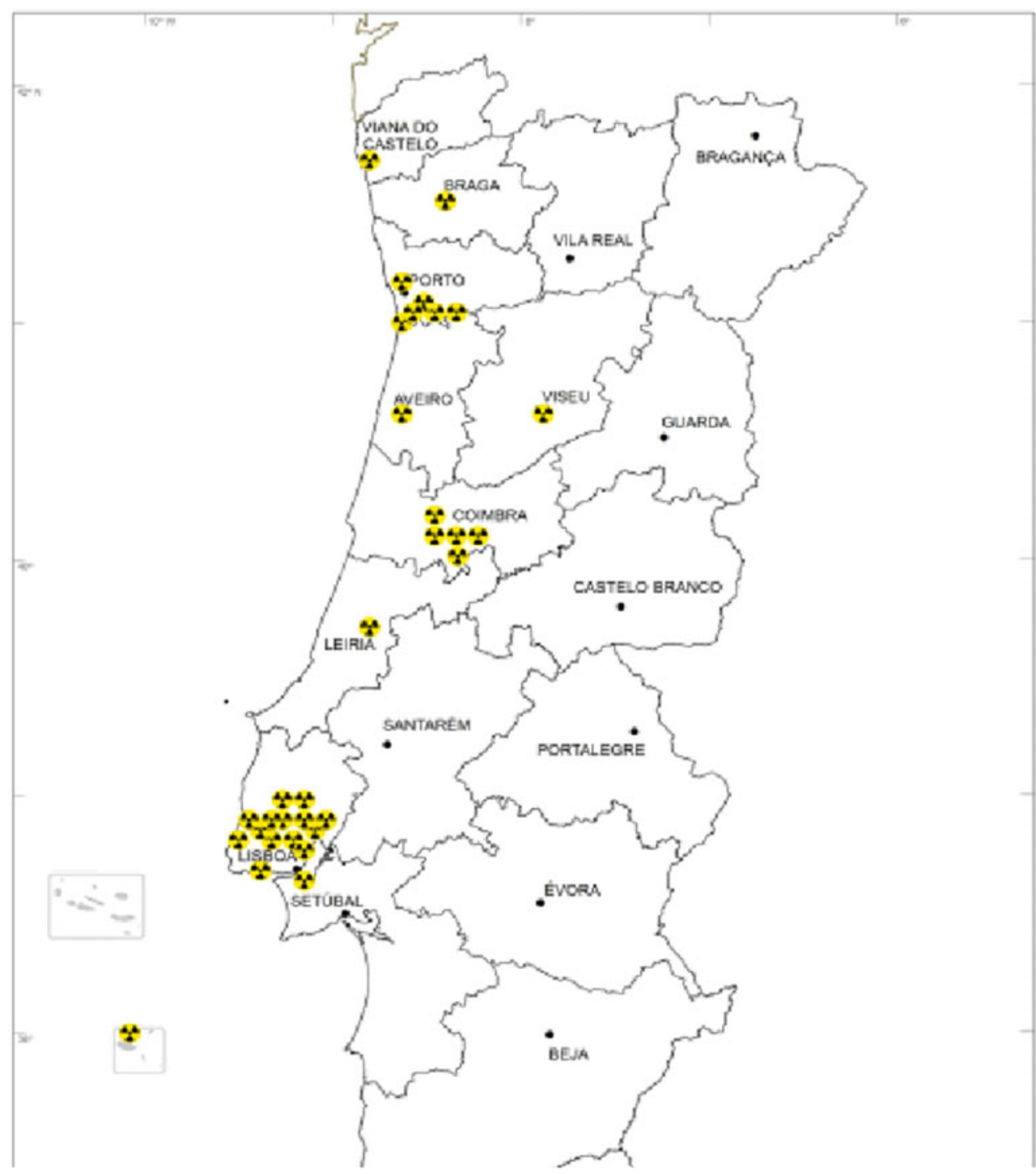

internship and region. Two residents were awarded the specialist title in 2010, four in 2011 and only one in 2012.

As described earlier, nuclear medicine is an independent specialty with a curricular training very similar to the one approved under the auspices of the European Union of Medical Specialists (UEMS) [2], namely concerning the minimum recommended numbers for diagnostic and therapeutic procedures.

During training, the resident is in an approved continuing education programme and is tested after each training module. For instance, after completing training in ${ }^{131} \mathrm{I}$ therapy procedures, both in benign and malignant disease, the resident will be asked to do a presentation regarding the work done in the area and could be submitted to an oral questionnaire. The same is done following each resident module. At the end of each year, a classification is given after an oral examination and, if approved, the resident can go to the next year of training.

At the end of the syllabus nuclear medicine training programme, the resident undergoes a final National Examination, which includes three parts: a curricular discussion, a practical test and a theoretical evaluation. In the practical session, the resident has to report on two examinations,
Table 1 Residents' distribution, by year of attendance and by region (December 2012 data)

\begin{tabular}{llccccc}
\hline & Region & 1st year & 2nd year & 3rd year & 4th year & Total \\
\hline No. of residents & North & 1 & 1 & 2 & 1 & 5 \\
& Centre & 1 & 1 & 1 & 1 & 4 \\
& South & 1 & 2 & 1 & 2 & 6 \\
& Total & 3 & 4 & 4 & 4 & 15 \\
\hline
\end{tabular}


discuss them and answer questions posed by the jury. The jury comprises five elements: the resident's primary tutor, the department head and three other nuclear medicine specialists named by the health authorities and by the Medical College.

In summary, the final assessment, covering both theoretical knowledge and practical abilities, is conducted by a five-element jury that includes specialists appointed by the government and by the College of Nuclear Medicine.

\section{Continuing education and professional development}

Regarding the postgraduate training after specialization, we organize courses and symposia, usually three or four per year on a nationwide basis and hold a national congress every other year. Residents are encouraged to apply for scholarships in order to do some training abroad and also to present their scientific work.

Concerning the clinical audit and the European Commission Guidelines on Clinical Audit for Medical Radiological Practices, certification of departments is encouraged, consisting of internal and external audits which testify that procedures are in accordance with the Manual of Good Practice which was compiled by the Medical College and published on its website. There are also two Portuguese specialists who attended one of the courses organized by the Committee for Accreditation of Nuclear Medicine Departments of the UEMS on Clinical Audit in Nuclear Medicine.

\section{International recognition}

So far, two Portuguese nuclear medicine specialists attended the annual Fellowship Examination of the UEMS/European Board of Nuclear Medicine (EBNM) [2] and therefore became FEBNM. Generally, this title has not been considered of primary importance in Portugal, due to the intensive evaluation to which residents are submitted, at the national level, during the residency. In the last meeting of the Medical College, this subject was brought up and it was proposed that it might constitute an added value. After an intense discussion, it was considered unnecessary and not providing a particular benefit for the practice of the specialty, apart from the fact that there is added expense, both for the specialist and for the Medical College.

The following members of the Portuguese nuclear medicine community have, or had, positions in international organizations:

Maria do Rosário Vieira

Visiting member (1990-1992) and permanent member (1992-1994) of the Education Group of the European Association of Nuclear Medicine (EANM)
Collaborator in the development of the basic curriculum for the specialty of nuclear medicine in Europe, 1993 and 1996

EANM Advisory Council (1995-1998)

Member of the Task Group and Committee Group for Radionuclide Therapy of the EANM (1997-2003)

Member of the editorial board of the European Journal of Nuclear Medicine and Molecular Imaging

EANM Delegate

UEMS/EBNM Delegate

João Manuel Pedroso de Lima

Portuguese representative at the EURATOM committees-Articles 31 and 37 (1991-1995)

President of Latin American Association of Societies of Biology and Nuclear Medicine (ALASBIMN) (20002002)

Portuguese Coordinator for the European School of Nuclear Medicine-ESNM_EANM (2001-2003)

Scientific consultant for the "Harvard Medical School —Portugal" programme (since 2010)

Ana Isabel Santos

EANM Paediatrics Committee

Lucília Maria Salgado

Member of the Directive Board of ALASBIMN (1997-2002)

EANM Cardiovascular Committee (2002-2010)

Member of the European Council of Nuclear Cardiology (since 2005)

EANM National Delegate

Paula Sofia Colarinha

EANM Paediatrics Committee (1998-2003)

Durval Campos Costa

Member of the EANM Task Group of NeuroNuclear Medicine (1988-1991).

Member of the EANM Committee of Neurology (1992-1994)

UEMS/EBNM President (2012-2015)

Editorial Board member:

Clinical and Translational Imaging: Reviews in Nuclear Medicine and Molecular Imaging

Computer Methods in Biomechanics and Biomedical Engineering: Imaging and Visualization

Quarterly Journal of Nuclear Medicine (until December 2012)

Neuroradiology (until 2010)

European Journal of Nuclear Medicine (until December 2005)

Section Editor:

UEMS/EBNM section, European Journal of Nuclear Medicine and Molecular Imaging 
"Functional and Molecular Neuroimaging", Neuroradiology (past)

"Image of the Month", European Journal of Nuclear Medicine (past)

Reviewer for several scientific journals, including The Journal of Nuclear Medicine, The European Journal of Nuclear Medicine and Molecular Imaging, Nuclear Medicine Communications, The Journal of Affective Disorders, Movement Disorders, Thorax, The Lancet and Neuroradiology.

\section{Final considerations}

In our country, nuclear medicine is a highly regarded specialty, namely in the last 20 years, especially since the advent of hybrid techniques, single photon emission computed tomography (SPECT)/CT and positron emission tomography (PET0/CT.

Another major area is the new therapies being performed by our specialty and also the therapies performed in the endocrinology field. These are highly differentiated procedures which are an integral part of our specialty and which confer upon it its autonomy.

We are somewhat apprehensive regarding the European proposals as concerns hybrid imaging. At the national level, we propose that the hybrid techniques SPECT/CT and $\mathrm{PET} / \mathrm{CT}$ remain within the nuclear medicine field and that there should be an increase in the length of training both in $\mathrm{CT}$ and MR during the residency period. So, our proposal is that there should be an increase in the length of the nuclear medicine residency and an increase in the length of the radiology component.

We acknowledge that it might be beneficial to hold a cycle of special studies/sub-specialization in hybrid imaging in the future, never less than within a 5-year time frame.

In the Medical College, we will begin analysing this possibility after a definitive proposal is set forth, so that the subject can be discussed fully within our Medical Society and a final decision might be reached at a future General Assembly of our Medical College.

Nuclear medicine is an independent specialty in our country; its curriculum is in full accordance with the syllabus of the UEMS and our residents are extensively audited [3]. Departments are accredited by the Medical College in order to verify their capacity to host nuclear medicine residencies.

Due to the above-mentioned reasons, we consider the teaching of nuclear medicine in Portugal to be of the highest level.

\section{References}

1. Programa de formação em Medicina Nuclear. Portaria n. ${ }^{\circ}$ 248/2012 de 17 de agosto Diário da República, 1. ${ }^{\mathrm{a}}$ série - N. ${ }^{\circ} 159-17$ de agosto de 2012

2. EANM site http://www.eanm.org/; UEMS/EBNM site http:// uems.eanm.org/

3. Ordem dos Médicos Site: https://www.ordemdosmedicos.pt/ 